\title{
A Cross-Cultural Exploratory Study of the Linkage between Emotional Intelligence and Managerial Effectiveness
}

\author{
by \\ Frank Shipper \\ Department of Management \\ Franklin P. Perdue School of Business \\ Salisbury University \\ Salisbury, MD 21801 \\ Phone: (410) 543-6333 \\ FAX: (410) 543-6208 \\ E-mail: fmshipper@ salisbury.edu \\ Joel Kincaid \\ Department of Economics \\ Franklin P. Perdue School of Business \\ Salisbury University \\ Salisbury, MD 21801 \\ Phone: (410) 548-4416 \\ E-Mail: jfkincaid@ salisbury.edu \\ Denise M. Rotondo \\ Department of Management \\ Franklin P. Perdue School of Business \\ Salisbury University \\ Salisbury, MD 21801 \\ Phone: (410) 548-5564 \\ E-Mail: dmrotondo@salisbury.edu \\ $\&$ \\ Richard C. Hoffman, IV \\ Department of Management \\ Franklin P. Perdue School of Business \\ Salisbury University \\ Salisbury, MD 21801 \\ Phone: (410) 548-5398 \\ E-Mail: rchoffman@salisbury.edu
}

Published citation: Shipper, F.M., Kincaid, J., Rotondo, D. and Hoffman, R.C. 2003. A Cross-Cultural Exploratory Study of the Linkage between Emotional Intelligence and Managerial Effectiveness. International Journal of_Organizational Analysis, 11(2): 171-191. 


\title{
A Cross-Cultural Exploratory Study of the Linkage between Emotional Intelligence and Managerial Effectiveness
}

\begin{abstract}
Multinationals increasingly require a cadre of skilled managers to effectively run their global operations. This exploratory study examines the relationship between emotional intelligence (EI) and managerial effectiveness among three cultures. EI is conceptualized and measured as selfother agreement concerning the use of managerial skills using data gathered under a 360-degree feedback process. Three hypotheses relating to managerial self-awareness of both interactive and controlling skills are examined using data from 3,785 managers of a multinational firm located in the United States (US), United Kingdom (UK), and Malaysia. The two sets of managerial skills examined were found to be stable across the three national samples. The hypotheses were tested using polynomial regressions, and contour plots were developed to aid interpretation. Support was found for positive relationships between effectiveness and EI (self-awareness). This relationship was supported for interactive skills in the US and UK samples and for controlling skills in the Malaysian and UK samples. Self-awareness of different managerial skills varied by culture. It appears that in low power distance (PD) cultures such as the United States and United Kingdom, self-awareness of interactive skills may be crucial relative to effectiveness whereas in high PD cultures, such as Malaysia self-awareness of controlling skills may be crucial relative to effectiveness. These findings are discussed along with the implications for future research.
\end{abstract}




\section{A Cross-Cultural Exploratory Study of the Linkage between Emotional Intelligence and Managerial Effectiveness}

Emotional intelligence (EI) holds the promise of capturing that elusive set of personal characteristics important to understanding the psychological and emotional growth necessary for personal success. The myriad positive outcomes predicted by high EI, especially in work settings, have not been produced using more traditional personal variables, such as personality traits or emotions at work, which should be analyzed in conjunction with situational factors to have strong predictive power. Even research on the Big Five, lauded for capturing important associations with work performance, has various and significant situational restrictions (c.f., Barrick \& Mount, 1991, 1993). EI transcends those limitations. EI, in effect, represents a construct that reflects personal characteristics and how they interact with and affect situations to impact behavior. Despite the appeal of EI, management researchers have not been quick to embrace the concept for various reasons.

There is considerable disagreement about how EI should be measured and serious questions about the respective psychometric properties of EI measures (Davies, Stankov \& Roberts, 1998; Jordan, 2000; Rozell, Pettijohn, \& Parker, 2000). Many researchers, however, steadfastly support the general claim that EI is critical to personal career success as well as

leadership effectiveness and organizational performance (Goleman, 1995, 1998; Mayer \& Salovey, 1993, 1995; Sosik \& Megerian, 1999).

Establishing the validity of EI is well beyond the scope of any one paper. However, the potential of EI warrants additional research to elucidate its effect on work outcomes. One issue not explored in the literature is the extent to which EI is a culturally relevant concept. If EI plays 
an important role in influencing performance-related outcomes in the US, does this potential exist in different cultures?

This paper seeks to explore the question of whether EI, conceptualized as managerial self-awareness, relates to managerial effectiveness in three cultural settings. Using data gathered under a 360-degree feedback process, we explore the nature of self-other agreement as an indication of self-awareness, the key to high EI (Goleman, 1995). The cultural aspects of EI and performance, when viewed from the perspective of self-other agreement, are examined by comparing results from the US, the U.K, and Malaysia.

Our inquiry will add to the current debate regarding the validity of EI by extending the knowledge regarding both its measurement and generalizability, especially across cultures. A brief literature review precedes the development of our hypotheses. A discussion of our results and implication for the future of EI inquiry conclude this paper.

\section{Concepts and Assessments of EI}

Perhaps the only consistent conclusion one can draw about research on emotional intelligence (EI) is that there is considerable inconsistency in how the construct is conceptualized and measured. Since EI was originally introduced by Salovey and Mayer (1990), formidable claims have been made about the dramatic impact high EI has on individual and organizational success (Goleman, 1995; Goleman, 1998). Others have been critical of the construct and the

research it has sparked (Ciarrochi, Chan, \& Caputi, 2000) citing a lack of empirical evidence of any true performance-enhancing effect for EI as well as serious measurement problems (Jordan, 2000).

Over-reliance on anecdotal evidence rather than empirical research has perhaps led to exaggerated claims of the importance of EI over and above what can be attributed to high IQ 
(Ciarrochi et al., 2000). Variations in how EI is measured and poor psychometric properties complicate the debate, leaving current researchers with the task of sorting out the facts. Clearly, addressing the measurement issues must take precedence over exploring the usefulness of EI, especially in organizational settings.

The variation in how EI has been measured is considerable. Researchers have used taskcompletion exercises similar to those on traditional IQ tests (Mayer, Caruso, \& Salovey, in press) as well as various behavioral measures including self and peer assessment (Bar-On, 1996; Jordan, Ashkanasy, \& Hartel, 2002) and 360 degree feedback (Boyatzis \& Goleman, 1999). Both methods have been criticized, however. Task-completion methods suffer from poor reliability (Ciarrochi, et al., 2000) and most behavioral measures include an overly broad range of behaviors and/or include factors not relevant to EI, per se (Jordan, 2000).

Self-report measures using paper-and-pencil instruments remain the most common method by which researchers have measured EI (Cooper \& Sawaf, 1996; Bar-On, 1996; Schutte, Malouff, Hall, Haggerty, Cooper, Golden, \& Dornheim, 1998; Sosik \& Megerian, 1999). Such self-report measures obviously suffer from self-assessment bias where a lack of true selfawareness and incentive to inflate responses confound the ability to accurately measure EI. Not only is the magnitude of such bias unknown, it is very likely unknowable. Though refinements of self-report measures have been attempted (Bar-On, 1996), some would argue these approaches fundamentally flawed.

Most would agree that self-awareness is the keystone to emotional intelligence. Selfawareness serves as the foundation for emotional and psychological growth necessary to achieve success (Goleman, 1995). To better assess true self-awareness, self-other comparisons have recently become a viable alternative to establish the presence of EI (Jordan, 2000; Jordan et al., 
2002; Sosik \& Megerian, 1999). By measuring the antecedents to self-awareness, such as purpose-in-life and public and private self-consciousness, EI is identified by comparing selfreport to reports from others in search of agreement. We take the position that self-other agreement is critical to establishing the presence of EI, however, the "others" must have sufficient knowledge of the referent individual to give reliable reports. Sosik and Megerian (1999), for example, found significant disagreement between manager self-reports and subordinate reports on many of the antecedents to self-awareness.

Low correlations between self and other reports on complex psychological constructs are not unusual (Shore, Tetrick \& Shore, 1998), thus work-based behavior and assessments of managerial skills may provide more reliable reports (Jordan, 2000). We question whether subordinates, for example, can accurately assess a manager's purpose-in-life. The same subordinate, though, should be able to accurately report how effectively the manager uses key skills or displays effective behaviors. This approach has been well established in the leadership literature (Bass, Cascio, \& O’Conner; 1974), and has been shown to provide meaningful positive relationships with performance and effectiveness (e.g., Shipper \& Dillard, 2000; Shipper \& Davy, 2002).

The only study to take this approach used samples of undergraduate students working in student teams (Jordan 2000). The potential for emotional immaturity (given the mean age of 19) and absence of any true manager-subordinate relationship or meaningful performance outcome presents a serious limitation to those results.

Our research uses 360-degree feedback data from managers and subordinates on two categories of managerial skills and compares the level of agreement between parties. We assert that high levels of agreement are indicative of higher managerial self-awareness, thus stronger EI 
in the manager. Managers with high EI (as indicated by high self-awareness) are expected to have higher performing units. This is consistent with Sosik and Megerian (1999) who found agreement on predictors of self-awareness to be more generally associated with higher performance than disagreement (viewed as over or underestimation) among 63 managers in the US

Our approach retains the elements identified in the literature as important to measuring EI reliably. We counter the problems found with self-report measures by considering self-other agreement and we seek information both parties have a reasonable likelihood of reporting accurately (i.e., presence of the manager's behaviors and skills). Inherent in this approach is the focus on self-awareness, which is key to EI, and the focus on work-related interpersonal effectiveness, the manifestation of high EI. The skills considered and our hypotheses follow.

\section{Interactive Skills}

Key to managerial effectiveness and essential to EI is one's ability to manage interpersonal relationships and facilitate positive leader-member relations. Managers who can regulate their own emotions, read others' emotions, effectively communicate, and resolve conflict in a positive way not only display high EI, but also facilitate high performance in their organizations. High EI in managers not only reduces subordinate anxiety, it allows for the employment of emotional awareness as a guide to one's behavior. This emotional utilization category of EI directly affects flexible planning, participation, creativity, redirections of effort and attention, motivation, and communication (Salovey \& Mayer, 1990). Such activities are inherent in effective management; therefore, those managers having higher EI would employ those skills most effectively to effectuate positive outcomes. 
Shipper \& Wilson (1992) have identified a cluster of skills similar to the activities identified as emotional utilization of EI (Salovey \& Mayer, 1990). Higher performance has been associated with managers making effective use of those skills that are termed interactive skills. These include abilities such as communicating goals (what and why), planning and problem solving, soliciting suggestions, coaching, training, supporting, providing feedback, delegating, and expressing appreciation or complimenting good work. Unlike some leadership research that focused on behavioral frequency, the interactive skills considered in this research are viewed from a mastery perspective. Because the interactive skills capture the manager's ability to effectively utilize the skills, we argue such mastery represents the employment of EI through behavior.

Research using 360-degree feedback data has found that high performing managers not only make better use of interactive skills but, important to this research, more accurately estimate their own skill levels when compared to low performing managers (Shipper and Dillard, 2000). Accurate skill estimation, measured by self-other differences by Shipper and Dillard (2000), would be indicative of high self-awareness, thus high EI. We hypothesize:

H1: High self-awareness, as indicated by high agreement between the manager and the subordinates on the manager's use of interactive skills, will be positively associated with managerial effectiveness.

\section{Controlling Skills}

Managers must establish goals and provide performance feedback. Part of this process incorporates the task of identifying performance problems and making corrections to ensure goal achievement. Controlling skills, identified by Shipper and Wilson (1992), include abilities such as keeping on schedule and meeting deadlines, applying appropriate control to details, and applying appropriate pressure to ensure goals are met. Managers effectively using controlling 
skills were evaluated as average and above on performance. Effective utilization of EI is believed to include redirected attention and motivation (Salovey \& Mayer, 1999), which is inherent in exercising control over goal accomplishment. Key to high EI would be the understanding that such skills must be used, but applied in an empathetic (rather than overbearing) manner. If a manager having higher EI did so, there should be a performance enhancing effect for managers using controlling skills. We expect:

$\mathrm{H} 2$ : High self-awareness, as indicated by high agreement between the manager and the subordinates on the manager's use of controlling skills, will be positively associated with managerial effectiveness.

\section{The Influence of Culture}

Regardless of how EI has been measured, the possibility for cultural relevancy has been largely ignored. The most common measures of EI include items that are likely to be problematic outside the US. For example, the WEIP5 (both self and peer report) contains the item "I can explain the emotions I feel to team members." The implication that emotions can (and should) be discussed is certainly not transferable to all cultures (Hofstede, 2001; Scherer \& Wallbott, 1994). Emotions are partially influenced by one's attitudes and beliefs. We define culture as the pattern of values, attitudes, and beliefs that affect the behavior of the peoples within a region (e.g., Hofstede, 2001; Ronen \& Shenkar, 1985). Given that cultures have been found to vary on a variety of fundamental values, attitudes, and assumptions (e.g., Hofstede, 2001; House \& Javidan, 2001; Ronen \& Shenkar, 1985), it is probable that emotional intelligence is likely to vary and even take on different meanings across cultures. Since we define the emotional intelligence of managers as their self-awareness of their skills (assessed by self and "other" reports), we argue that cultural differences in EI are likely to stem from two sources. The first of these are cultural differences in certain characteristics related to self-awareness and secondly, the 
cultural variations that have been observed in research on the effectiveness of managerial behaviors and skills.

As stated earlier, our study is conducted among three national cultures: Malaysia, United Kingdom, and United States. These were selected for a number of reasons. First, the inclusion of the US, the UK and Malaysia enables us to extend past cross-cultural research on managerial behaviors since much of it has been conducted in Europe and North America (Yukl, 1998). Moreover, while both the United States and the United Kingdom form part of the Anglo culture (Ronen \& Shenkar, 1985), the social culture of the two nations are not the same (e.g., Hickson \& Pugh, 1995) and their inclusion may allow us to observe such distinctions. The inclusion of Malaysia serves two purposes. It permits us to examine the effectiveness of managerial skills in a far eastern culture. Such cultures are not frequently represented in such cross-cultural studies (Yukl, 1998). Moreover, unlike the other two nations, Malaysia is more ethnically diverse suggesting more sub-cultures that may tolerate a wider variety of management practices than either the UK or US. Finally, the three locations of our research site agreed to participate in our study. Some of the characteristics of each culture are depicted in Table 1.

We have selected Hostede's four cultural dimensions as the major descriptors of culture because they offer a widely accepted typology that has received much support in managerial research. Furthermore, the results of more recent cultural value studies seem to support the stability of the dimensions (House \& Javidan, 2001; Hoppe, 1990; Helmreich \& Merritt, 1998). The use of this typology will also facilitate comparisons with previous research.

At the core of our approach to EI is self-awareness. The concept of "self" as defined by the individual apart from others is not shared by all cultures. Collectivist cultures define self in the context of others such as a family, or tribe. In collective traditions a person rarely thinks of 
themselves as an individual (Hofstede, 2001). Thus, self-awareness may simply not be perceived as relevant for effective behavior in those cultures. Cultures also vary on uncertainty avoidance or tolerance for ambiguity. Lynn and Martin (1995) found that low uncertainty avoidance (having a tolerance for ambiguity) is more strongly associated with emotional stability and subjective well being. These characteristics are important for self-awareness and thus EI. EI may not be the same in cultures that do not focus on self and do not exhibit some of the personality traits that seem to support EI. Furthermore, Hartzing (1999) observed that people from low power distance (social equality is valued) cultures were more willing to provide information to someone who is not a superior. High power distance cultures have a strong respect for authority and are not likely to question or criticize a superior (Hofstede, 2001). Thus, providing accurate information on a superior's skills, as our method requires, may not be a task that is comfortably taken in all cultures. The above suggests that culture may influence both the concept and measurement of EI and thus is likely to produce differing results regarding the relationship between a manager's EI and effectiveness.

There is a considerable body of research suggesting that preferences for using certain managerial behaviors or skills vary by culture, thus providing further evidence that the EIeffectiveness relationship is likely to differ among cultures. We examine some examples of culture's influence on both the interactive and controlling skills described previously. While Dorfman, et al. (1997) found that certain interactive skills such as supporting, recognition by contingent reward, and charismatic behaviors seem to be universal across cultures, other skills such as participation and the use of contingent punishment are not. Participative planning and problem solving skills appear to be contingent upon one's culture. Haire, et al. (1966) found national variations on the use of these behaviors. More recently, Pavett and Morris (1995) found 
that higher power distance values within a culture were associated with less participative management. On the other hand, cultures with collective and more feminine (cooperation, relations) values are associated with group decisions and seeking consensus (Hofstede, 2001) both of which are conducive to more participative managerial behaviors. Providing direct feedback on performance is viewed as a threat in collective societies (Hofstede, 2001) and may not have the desired outcome in such a cultural setting. It suffices to say that different cultural orientations appear to affect the efficacy of the use of certain interactive skills.

Controlling skills such as goals, schedules and control of details are also influenced by culture. For example, similar directive behaviors were found to vary considerably among cultures in the Dorfman, et al. (1997) study. High uncertainty avoidance cultures favor schedules and the control of details to reduce the uncertainty of tasks. Goal pressure to produce results is a characteristic of masculine (competitive, results -oriented) cultures (Hofstede, 2001).

Different cultural orientations affect the choice of preferred managerial skills likely to be effective in the cultural milieu. Moreover, one's cultural orientation also influences one's concept of self and comfort with rating the behavior of others. Malaysia differs from both the US and UK on self-orientation and power distance (See Table1). Consequently, we expect there to be some differences across cultures on the relationship between high self-awareness and managerial effectiveness. With the paucity of research on self-awareness in different cultures, we are reluctant to make specific hypotheses.

H3: In the US and UK, the pattern of results will be similar for high self-awareness and managerial effectiveness, whereas in Malaysia the results are expected to differ.

\section{Method}

This study was conducted using managerial employees in a large multi-national corporation. The total sample on which the psychometric properties of the instrument were tested 
consisted of 5985, 23\% was female and 77\% male, with an average age of 40 and having an average of nine years with the company. For the samples from different cultures, biographical data in personnel files were consulted to select only those individuals who were both citizens and residents of the country in which they were working. The US sample consisted of 3340, $23 \%$ female and $77 \%$ male, with an average age of 41 and ten years with the company. The United Kingdom sample consisted of 208, $18 \%$ female and $82 \%$ male, with an average age of 37 and seven years with the company. The Malaysian sample consisted of $237,22 \%$ female and $78 \%$ male, with an average age of 40 and 12 years with the company. Procedures to control for sample size effects are described later in the analysis section.

\section{$\underline{\text { Data Collection }}$}

The procedure used for collecting the data on managerial skills was to ask five associates of each manager, and the manager to respond to the Survey of Management Practices (Form LB). The questionnaires were given to the associates in their work areas. They were asked to complete them on their own. The individuals were given an envelope in which to seal and return the questionnaire. The response rate of the associates was $63 \%$ or 3.15 responses per manager. In addition, each manager's superior was asked the four questions regarding the group's effectiveness described previously.

\section{$\underline{\text { Measures }}$}

Managerial skills were assessed using a structured questionnaire, The Survey of Management Practices (Form LB) (SMP) to collect observations (Wilson \& Wilson, 1991). It was chosen for two reasons: first, its comprehensive nature and second, the psychometric soundness of earlier versions (Clark, Clark, \& Campbell, 1992; Koser \& Lussier, 1987; Leslie \& Fleenor, 1998; Morrison, McCall \& DeVries, 1978; Shipper, 1995; Shipper \& White, 1998; Van 
Velsor \& Leslie, 1991). The questionnaire consists of 71 items of which 48 were used in this study. Forty-four of these items were selected because they constitute the scales for the managerial skills hypothesized in the Managerial Task Cycle model (Wilson, O’Hare \& Shipper, 1990). Four other items were selected because they are indicators of managerial effectiveness. Only the manager's superior's responses to the latter four items were used in this study to avoid the problem of common source variance. The latter set of items is discussed in more detail later in this section.

Prior versions of the questionnaire have previously been examined for test/re-test reliability, internal consistency, interrater reliability, construct validity, and criterion validity (Rosti \& Shipper, 1998; Shipper, 1995; Shipper \& White, 1998; Wilson, 1975, 1978). All of the scales within the instrument have been reported in prior studies to exceed Nunnally's (1978) criteria of .70 for reliability in exploratory research. Since this is a new version of the instrument, all of the scales were retested for internal consistency in this study and found to exceed Nunnally's criteria as reported in Table 2. In addition, the scales were tested also for interrater consensus using the Interrater Agreement Index $\left(r_{W G(J)}\right)$ (James, Demaree, \& Wolf; 1984). The average Interrater Agreement Indexes reported in Table 2 were calculated using the observed variances reported in Shipper (1995) for the expected variance.

Most of the instruments available to gather observations on managerial behaviors focus on frequency (Bernardin \& Beatty, 1984; Schriesheim \& Kerr, 1974; Shipper, 1991; Van Velsor \& Leslie, 1991; Yukl, 1989). Competency and not frequency however, is the important attribute concerning subunit performance (Van Velsor \& Leslie, 1991). In the managerial-skill scales, both the anchor and the stem focus on competency and not just frequency (Wilson \& Wilson, 1991). For example, the scale anchors are "extremely small extent, never, not at all" and 
"extremely great extent, always." Each scale consists of three to five items. Stems for three typical items are as follows: This manager (i.e., supervisor) plans the work so it keeps running smoothly, gets advice from the group on the best way to do things, and compliments individuals who contribute significantly to the group's effort. One of the subtle differences in this questionnaire is that qualifying words such as "running smoothly" are included in the stem.

As discussed previously, managerial effectiveness was assessed with four items that were asked of the managers' superior. These items ask if the group "works well," "does high quality work," "is very productive," and "has a very positive impact on the organization." Cronbach's alpha for this scale is $.72(n=2128)$.

$\underline{\text { Analysis }}$

Since the individual of interest in this study is the manager, the average score for all individuals who responded to the questionnaire within a work unit was used as the measure for each scale as has been done in prior studies (e.g., Atwater \& Yammarino, 1992; Hegarty, 1974). Theoretically, such aggregation is appropriate when studying managers because it reduces random error and perceptual differences among observations by others (Campion, 1988). Empirically, calculating the index of interrater agreement and eta squared $\left({ }^{2}\right)$ for each scale can evaluate the appropriateness of such aggregation (Prussia \& Kinicki, 1996). The interrater agreement indexes and etas squared reported in Table 2 suggest strong within-groups agreement and thus, aggregation is justified. All etas squared were significant at the .0001 level.

To partially test if the measures of interactive and controlling skills are independent, factor analysis was used. To test the stability of the factor analysis, the US sample was randomly split in half and factor analysis was done on each half. As is common practice a rotated solution based on principle components and factors with eigenvalues greater than one was used. Based on 
the standardized score coefficients from each analysis, factor scores were computed across the two halves and correlated with one another. This procedure was followed for both self and associates responses to the instrument. All correlation coefficients were greater than $.99(\Delta<$ $.001)$ indicating that the results are stable.

This same procedure was used to test the stability of the factor structure across the different cultures. The results are reported in Tables 3 and 4. All correlation coefficients were greater than $.92(\Delta<.001)$ indicating that the results are stable across cultures.

The concept of self-awareness is operationalized as a relationship between two independent variables: self report of skill use and associates' report of use of the same skill. The congruence (non-congruence) of self-other reports represents higher (lower) self-awareness. Our hypothesis is that higher self-awareness should be associated with higher levels of managerial effectiveness.

Self-awareness was examined for each factor in each culture. Each factor was examined using polynomial regression for self and associates' scores as independent variables and effectiveness as the dependent variable. This form of testing introduces multiple quadratic terms, but avoids questions regarding the appropriateness of subtracting of what may be non-interval scales (Edwards, 1994). The second-order terms used in polynomial regression are difficult to understand and interpret without graphical representation of the results, which we use to represent our findings.

To prepare the data for each analysis, the data were smoothed using a non-uniform rational B-splines procedure. This procedure was applied to reduce random error variances in the data and to partially control the impact of outliers. The smoothing procedure was chosen because it is considered to be "a very conservative" technique (SPSS, 1997, p. 6-9). In addition, the data 
was interpolated to a uniform grid using the Renka I procedure. This step was taken to have the same sample sizes for all three cultures to ensure that the findings were comparable across cultures and not sample size dependent. The Renka I procedure was strongly recommended due to its robustness and accuracy (SPSS, 1997, p. 7-3).

Ordinary least squares could have been used to estimate the above specification. However, polynomial regression offers several advantages over ordinary least squares. First, it uses a form of local regression where the response surface is estimated piece-wise (i.e. using Bsplines). Such an approach is advantageous because it is more robust against outliers and therefore better able to produce representative estimates of the response surface, especially when there is substantial variation in the height of the surface (Venables and Ripley, 2002). Second, it is ideal for exploratory investigations such as ours, where one does not have a particular functional form of the regression dictated by theory.

Managerial effectiveness can be thought of as a 'response surface' to be estimated, and, with the presence of two independent variables, can be visualized in three dimensions. Such displays are effective to the extent that one has the ability to rotate such figures in space. Given the static nature of our displays, we have generated filled-contours to visualize and explicate the relationships among reported self-other skill use and managerial effectiveness (Ihaka \& Gentleman, 1996). Contour graphs reduce the dimensions from three to two and are well suited for static presentations. Furthermore these two-dimensional displays allow the reader to quickly grasp the global properties of the relationships explored.

The estimated response surface is visualized as a map, where each point on the map is associated with two sets of values: a measured level of effectiveness and a paired value of selfother reported skill use. These paired values can be used in a manner analogous to latitude and 
longitude to locate a particular point on this 'response surface' and thus a particular level of managerial effectiveness. Consider Figure 1, where the x-axis is the managers' self-reported level of interactive skill use and the y-axis is the associates' report of the manager's skill use in the US.

The levelplot (Cleveland, 1993; Thaka \& Gentleman, 1996) in Figure 1 is composed of two elements: the left most being a filled contour plot of the response surface, and on the right, a key correlating gray levels with ranges of managerial effectiveness. We have adopted the standard that higher levels of effectiveness are denoted by darker shades of gray and lower levels of effectiveness correspond to lighter shades of gray. On the graph, regions that share the same gray level also share similar values of managerial effectiveness. For example consider two points: D and D'. Point D' corresponds to the paired value of reported self-other skill use of -2 and 2. Point $\mathrm{D}$ corresponds to the paired values of 2 and -2 . Each point lies in a region of the same gray value and thus should have similar values of managerial effectiveness associated with them. Indeed this is the case; point D has a value of 4.6, while point D' has a value of 4.28.

We have augmented Figure 1 with two lines that are used to indicate those self-other reports that correspond to perfect agreement or disagreement. The dotted line running from the lower left corner $(-3,-3)$ to the upper right corner $(3,3)$ is the perfect agreement line, whereas the line running from the upper left corner $(-3,3)$ to the lower right corner $(3,-3)$ indicates perfect disagreement. Note that along the perfect agreement line, all points correspond to identical selfother scores. On the line of perfect disagreement, each point corresponds to a paired self-other score where one party reported exactly the opposite of the other party.

Recall that H1 says that high self-awareness (and by extension high levels of EI) should be correlated with high levels of managerial effectiveness. This hypothesis would be supported if 
one observed that those points on or near the perfect agreement line tended to be associated with higher levels of managerial effectiveness; whereas, points along the perfect disagreement line were associated with lower levels of managerial effectiveness. This indeed appears to be the case, at least for interactive skill use in the U S (see Figure 2). In general, the perfect agreement line lies on the darker regions of the graph indicating that agreement is associated with higher levels of managerial effectiveness. A complete discussion of our results follows.

\section{Results}

The results are reported in Table 5 and portrayed in Figure 2. All of the equations were highly significant, and 20 of the 36 individual terms were also significant. The amount of explained variance for the six equations ranged from 28 to $72 \%$ suggesting that self-awareness has, even at the lowest level, what Guilford (1956) would classify as a substantial correlation with managerial effectiveness.

\section{$\underline{\text { Mathematical Results }}$}

All the equations have one or more significant exponential terms and all the equations have significant binomial terms. For instance, the US interactive results yield an $\mathrm{x}^{2}$ term significant at the $\mathrm{p}<.00001$ level, and the Malaysia controlling results yield a $\mathrm{y}^{2}$ term significant at the $\mathrm{p}<.00001$ level. Thus, curvilinear surfaces rather than either lines or planes better represent the six individual results.

Therefore, these results suggest that regardless of the culture, the relationship between self-awareness and managerial effectiveness does not appear to be simple. Furthermore, the results suggest that a significant amount can be learned about managerial effectiveness if selfawareness is examined using polynomial regression. Hence, the findings of this study appear to 
support the use of this technique as proposed by Edwards (1994) for examining such relationships.

\section{Graphical Results}

The results are summarized in a series of six contour plots depicted in Figure 2

Figure 2 is a trellis plot (Cleveland, 1993), where each panel represents an individual levelplot for a specific combination of country and skill. We examine three countries and two types of skills in this study and thus there are (2x3) six individual panels of data. To assist in comparing each relationship between self-other reported skill use and managerial effectiveness across countries and skill-type, each panel in the trellis display has the same $\mathrm{x}$ and $\mathrm{y}$-axis limits, and all use the same gray scale key to indicate the level of managerial effectiveness.

Overall, the results provide moderate support for $\mathrm{H} 1$. $\mathrm{H} 2$ received some support. $\mathrm{H} 3$ was partially supported in that the data from Malaysia generated a pattern of results that differed from the US and UK samples.

High self-awareness regarding interactive skills was positively associated with managerial effectiveness in both the US and UK samples providing support for the first hypothesis. This is depicted in the two contour plots on the left of Figure 2 (see also Table 5) where regions of agreement correspond to darker shades of gray, thus higher effectiveness levels. Within the Malaysian sample, interactive skills related to higher managerial effectiveness in the regions of self-other disagreement (representing low self-awareness) contrary to the first hypothesis.

High self-awareness regarding controlling skills was positively associated with managerial effectiveness in both the UK and Malaysian samples providing support for the second hypothesis as depicted in the three contour plots on the right of Figure 2 (see Table 5). 
Within the US sample, managerial effectiveness was positively related to controlling skills in the region of superior-subordinate disagreement, indicating low self-awareness, contrary to the second hypothesis.

Partial support was found for hypothesis three for interactive skills but not for controlling skills. In both the US and UK samples, high self-awareness of interactive skills was positively related to managerial effectiveness. In the Malaysian sample the opposite was true, low selfawareness was associated with higher effectiveness, thus supporting the hypothesis. In the case of controlling skills the results were similar between the UK and Malaysian samples while the US results were the opposite of those found in the other two samples contrary to the hypothesis. Higher levels of self-awareness of controlling skills were positively related to managerial effectiveness in both the UK and Malaysian samples. Whereas, low levels of self-awareness of controlling skills was positively associated with higher levels of managerial effectiveness within the US sample.

For both sets of skills, the results also reveal that the relationship between EI and effectiveness is fairly complex. For example, even though the general pattern of the relationship between self-awareness of interactive skills and effectiveness was similar in the US and UK samples, we can observe that high effectiveness is only associated with agreement on the skill use in the UK. In the US high effectiveness also occurs where there is agreement that the manager does not use such skills. Likewise, agreement on controlling skills leads to higher effectiveness in the UK sample, but effectiveness is associated with both agreement and disagreement on controlling skills in the Malaysian sample. 


\section{Discussion}

This study examined whether EI, conceptualized and measured as high managersubordinate agreement on the manager's use of interactive and controlling skills, was positively associated with managerial effectiveness in three countries. Our purpose was twofold. First, we wanted to establish whether self-other agreement is an appropriate way to measure EI by seeking reports about the manager's ability to effectively use important work skills rather than reports of the manager's emotional and personal adjustment. This approach is not novel, but is relatively recent in the EI literature (Jordan 2000). Second, we sought to explore whether the concept of agreement (thus, self-awareness and EI) were important predictors of managerial effectiveness in cultures outside the US. Our results give insight into both questions that are important for future research into EI and work performance.

\section{Does Agreement Matter?}

With some exception, it appears that manager-subordinate agreement on the manager's use of skills does tend to correspond to higher unit effectiveness. The data do provide good support for $\mathrm{H} 1$ and $\mathrm{H} 2$, which predicted agreement to be associated with higher effectiveness ratings than disagreement. This can be seen in all levelplots except the US controlling skills plot and the Malaysian interactive skills plot. Regions of agreement correspond to higher levels of effectiveness for the manager as reported by the manager's superior. We would conclude agreement does matter and does represent conditions where the manager exhibits higher EI through his or her behavior.

\section{Agreement on Interactive Skills}

When the manager and the subordinates agreed on the manager's use of interactive skills, effectiveness tended to be higher than when the parties disagreed (at least for the US and UK 
samples). Agreement about higher levels of interactive skills use tends to correspond to higher managerial effectiveness levels than when both parties agree lower levels of interactive skills are used. (Note that the highest effectiveness levels occur in the region of the US and UK graphs (top right corners) where both the manager and subordinates agree on higher skill use. However, particularly relevant to the importance of EI in work settings is the comparison between levels of skill use, levels of agreement, and effectiveness ratings. Even when both the manager and the subordinates agreed the manager was low on interactive skills, effectiveness levels were higher than for combinations where the parties disagreed (when either the manager or the subordinates—but not both—reported the manager made high use of interactive skills).

This finding can be explained well when placed within the framework of the importance of EI. Greater self-awareness would likely lead to managers knowing they are deficient or weak in a particular skill area, thus perhaps compensating for that deficiency in other ways. The ability to recognize a personal weakness and work around it to the benefit of the work group describes the manner by which one with high EI would operate. Those who argue for the importance of EI would see such an awareness of a weak skill area as likely to incite greater self-motivation and more effective relationship management in such a manager so that subordinate anxieties and negative emotions are ameliorated. If self-awareness were not important, we would find the highest effectiveness levels corresponding to the regions of the graph where higher levels of interactive skills use are represented (in other words, in the region above the perfect disagreement line which runs from the top left to the bottom right). This is not the case.

\section{$\underline{\text { Agreement about Controlling Skills }}$}

Agreement between the manager and subordinates on the use of controlling skills seems to follow a similar pattern as found with interactive skills. In the UK and Malaysian samples, 
higher effectiveness corresponded to conditions of relative agreement. And as with interactive skills, one expects agreement on the use of controlling skills to be associated with high effectiveness, and regions of disagreement to correspond with lower effectiveness levels than regions of agreement where managers make low use of controlling skills. Once again, even agreement on low use of controlling skills, which reflects higher levels of managerial selfawareness, was associated with effectiveness. This occurs perhaps because the manager compensates effectively for a weak skill area.

In the US sample the highest effectiveness levels were found under conditions of perfect disagreement. This being said, the effectiveness levels corresponding to perfect agreement (bottom left to top right) were relatively uniform and not accurately labeled as "poor." Disagreement on the manager's use of controlling skills in the US, however, corresponds to more volatile performance. This finding is unexpected in that we would predict controlling skills to be important to unit performance. It is possible that it is not socially desirable in the US culture to report use of controlling skills. It is also possible that in high performing units, there may be unique contextual elements that make controlling skills important but not contingent on agreement about the manager's skill level. Clearly this is a finding that should be re-tested in other settings.

\section{Cultural Implications}

The results indicate that the relationship between self-awareness and effectiveness needs to be explored controlling for culture. It appears that in low power distance (PD) cultures such as the United States and United Kingdom, self-awareness of interactive skills may be crucial relative to effectiveness whereas in high PD cultures such Malaysia, self-awareness of controlling skills may be crucial relative to effectiveness. These findings follow from Hofstede's 
(2001) suggestion that different cultures value different managerial behaviors. Thus, the need for self-awareness of different managerial skills varies by culture. Moreover differences in the EIeffectiveness relationship where also found between the US and UK suggesting differences not captured by Hofstede's (2001) broad cultural dimensions.

\section{Limitations}

This study, like most other studies, has a number of limitations. First, all the data were gathered within a single multinational corporation that is known to have a strong internal culture. This limitation also applied to Hofstede's (2001) work (Offermann \& Hellmann, 1997). The results, however, do not appear to be overwhelmed by the organizational culture.

A second limitation is that the results are based on a single 360-degree instrument. This instrument was selected because of its psychometric soundness and prior use in cross-cultural research (e.g., Offermann \& Hellmann, 1997). As has been pointed out in reviews of 360 instruments over the years, not all such instruments meet even basic criteria of psychometric soundness. In fact, the instrument selected is the only one that met the basic criteria for inclusion in all three reviews (Leslie \& Fleenor, 1998; Morrison, McCall, \& DeVries, 1978; Van Velsor \& Leslie, 1991). Thus, extending these results to the use of other 360 instruments without testing them first could lead to erroneous conclusions.

A third limitation of this study is that a categorical approach to discrepancy measures was not used in this study as has been done by others (e.g., Atwater \& Yammarino, 1992; Van Velsor et al., 1992). They were not included because the categorization of a scale reduces the accuracy or the amount of information contained in the analysis. In addition, Church's (1997) comparison of categorical versus linear scaled data found that the results were similar. Thus, not including a 
categorical approach to discrepancy scores improves the parsimony of the study without any loss of information.

Finally, data-smoothing approach is not, however, without its limits. Most importantly, the smoothing approach is distribution free and must therefore be used with caution if such results are to be used in a predictive manner. Furthermore, one must also be careful not to overinterpret a single result. While these are real limitations, they impact our work marginally because we are not engaged in a predictive exercise, and we are relying on a set of results, rather than a single outcome, to judge whether or not the data has put the lie to our hypothesis.

\section{Conclusions}

At least three conclusions can be drawn from this study. First, this study raises interesting questions about the nature of self-awareness, EI, and managerial effectiveness. Observing high levels of effectiveness among work units where both the manager and associates agree the manager's level of skill use (and mastery) is low is intriguing. Given the substantial evidence that high levels of skill use are essential to overall unit performance, the results here would be consistent with claims that high self-awareness and EI have an independent and important influence on managerial functioning and behavior. Future research should pursue these relationships in other settings and across different cultures

First, the results of this study indicate that the relationship between self-awareness and managerial effectiveness is more complex than has been previously thought. The culture, the content of the instrument, and the method of measuring self-awareness can all interplay in determining the strength of the relationship found between self-awareness and managerial effectiveness. Future investigation of this relationship should include all these considerations. 
Second, the two factors derived from the managerial skill scales of the SMP are relatively stable across the cultures investigated. Naturally additional studies are needed to test this finding across other cultures. In addition, other instruments should be tested across cultures to ensure that the instrument does not determine the finding.

Third, interpreting 360 instruments should be done cautiously in cultures different from that in which the instrument was developed. Obviously, from reviews of 360 instruments not all of them have been rigorously developed (Leslie \& Fleenor, 1998; Morrison, McCall, \& DeVries, 1978; Van Velsor \& Leslie, 1991). Even one that has been through a number of iterations in its development and has been found to be psychometrically sound (Clark, Clark, \& Campbell, 1992; Koser \& Lussier, 1987; Leslie \& Fleenor, 1998; Morrison, McCall \& DeVries, 1978; Rosti \& Shipper, 1998; Shipper, 1995; Shipper \& White, 1998; Van Velsor \& Leslie, 1991) cannot be interpreted similarly across cultures without additional testing. Thus, additional cross-cultural testing of 360 instruments, and indeed the nature of evaluation from multiple sources, needs to take place. 


\section{References}

Atwater, L. E., \& Yammarino, F. J. 1992. Does self-other agreement on leadership perceptions moderate the validity of leadership and performance predictions? Personnel Psychology, 45: 141-164.

Bar-On, R. 1996. The emotional quotient inventory (EQ-I): A test of emotional intelligence. Toronto: Multi-Health Systems.

Barrick, M. R., \& Mount, M. K. 1991. The Big Five personality dimensions and job performance: A meta-analysis. Personnel Psychology, 44: 1-26.

Barrick, M. R., \& Mount, M. K. 1993. Autonomy as a moderator of the relationship between the Big Five personality dimensions and job performance. Journal of Applied Psychology, 78: $111-118$.

Bass, B. M. 1990. Bass \& Stogdill's handbook of leadership: Theory, research \& managerial applications (3rd ed.). New York: Free Press.

Bass, B. M. Cascio, W. F., \& O’Connor, E. J. 1974. Magnitude estimations of expressions of frequency and amount. Journal of Applied Psychology, 59: 313-320.

Bernardin, H. J., \& Beatty, R. W. 1984. Performance appraisal: Assessing human behavior at work. Boston: Kent Publishing.

Boyatzis, R. \& Goleman, D. 1999. Emotional competence inventory 360 (ECI 360). Information available at http://www.eiconsortium.org/eci_360.htm.

Campbell, D. 1991. Manual for the Campbell leadership index. Minneapolis: National Computer Systems, Inc.

Campion, M. A. 1988. Interdisciplinary approaches to job design: A constructive replication with extensions. Journal of Applied Psychology, 78: 467-481. 
Church, A.H. 1995. First-rate multirater feedback. Training \& Development, 49(8): 42-43.

Church, A. H. 1997. Managerial self-awareness in high-performing individuals in organizations. Journal of Applied Psychology, 82: 281-292.

Ciarrochi, J. V., Chan, A. Y. C., \& Caputi, P. 2000. A critical evaluation of the emotional intelligence construct. Personality and Individual Differences, 28: 539-561.

Clark, K. E., Clark, M. B., \& Campbell, D. P. 1992. Impact of leadership. Greensboro, NC: Center for Creative Leadership.

Cleveland, W. S. 1993. Visualizing Data. Summit, NJ: Holbert Press.

Cooper, R. K., \& Sawarf, A. 1996. Executive EQ: Emotional intelligence in leadership and organizations. New York: Grossett/Putnam.

Davies, M., Stankov, L., \& Roberts, R. D. 1998. Emotional intelligence: In search of an elusive construct. Journal of Personality and Social Psychology. 75: 989-1015.

Dorfman, P. W., Howell, J. P. Hibino, S., Lee, J.K., Tate, U., \& Bautista, A. 1997. Leadership in western and Asian countries: Commonalities and differences in effective leadership processes across cultures. Leadership Quarterly, 8: 233-274.

Edwards, J. R. 1994. The study of congruence in organizational behavior research: Critique and a proposed alternative. Organizational behavior and Human Decision Processes, 58: 51100.

Goleman, D. 1995. Emotional intelligence. New York: Bantam.

Goleman, D. 1998. Working with emotional intelligence. New York: Bantam.

Guilford, J. P. 1956. Fundamental statistics in psychology and education. New York: McGrawHill. 
Haire, M., Ghiselli, E. E. Porter. 1966. Managerial thinking: An international study. New York: John Wiley.

Hartzing, A. W. K. 1999. Managing the multinationals: An international study of control mechanisms. Cheltenham, England: Edward Elgar.

Hegarty, W. H. 1974. Using subordinate ratings to elicit behavioral changes in supervisors. Journal of Applied Psychology, 59: 764-766.

Helmreich, R. L. \& Merritt, A. C. 1998. Culture at work in aviation and medicine: national, organizational and professional influences. Aldershot, England: Ashgate.

Hickson, D. J. \& Pugh, D. S. 1995. Management worldwide: The impact of societal culture on organisations around the globe. London: Penguin Books.

Hofstede, G. 2001. Culture's consequences, $2^{\text {nd }}$ ed. Beverly Hills, CA: Sage.

Hoppe, M. H. 1990. A comparative study of country elites: international differences in workrelated values and learning their implications for management training and development. Unpublished doctoral dissertation, University of North Carolina at Chapel Hill.

House, R. J. \& Javidan, M. 2001. Cultural acumen for the global manager: Lessons form project GLOBE. Organizational Dynamics, 29: 289-305.

Ihaka, R. \& Gentleman, R. 1996. R: A language for data analysis and graphics. Journal of Computational and Graphical Statistics, 5: 299-314.

James, L. R., Demaree, R. G., \& Wolf, G. 1984. Estimating with-in group interrater reliability with and without response bias. Journal of Applied Psychology, 69: 85-98. 
Jordan, P. J. 2000. Measuring emotional intelligence in the workplace: A comparison of self and peer ratings of emotional intelligence. Paper presented at the Academy of Management meetings, August 2000. Toronto, Canada.

Jordan, P. J., Ashkanasy, N. M., Hartel, C. E. J., \& Hooper, G. 2002. Workgroup emotional intelligence: Scale development and relationship to team process effectiveness and goal focus. Human Resource Management Review, 12: 195-214.

Koser, K., \& Lussier, R. R. 1987. A summary of the research related to middle management. Long Beach, Veterans Administration Medical Center.

Leslie, J. B., \& Fleenor, J. W., 1998. Feedback to managers: A review and comparison of multi-rater instruments for management development $\left(3^{\text {rd }}\right.$ ed.). Greensboro, NC: Center for Creative Leadership.

Lynn, R. \& Martin, T. 1995. National differences for 37 nations in extroversion, neuroticism, psychoticism, and economic, demographic and other correlates. Personality and Individual Differences, 19: 403-406.

Mayer, J. D., Caruso, D. R., \& Salovey, P. in press. Emotional intelligence meets the traditional standards of an intelligence. Intelligence.

Morrison, A. M., \& McCall, J., DeVries. 1978. Feedback to managers: A comprehensive review of twenty-four instruments. Greensboro, NC: Center for Creative Leadership.

Nunnally, J. C. 1978. Psychometric theory. New York: McGraw-Hill.

Offermann, L. R. \& Hellmann, P.S. 1997. Culture's consequences for leadership behavior: National values in action. Journal of Cross-cultural Psychology, 28: 342-351.

Pavett, C. \& Morris, T. 1995. Management styles within a multinational corporation: a five country comparative study. Human Relations, 48: 1171-1191. 
Prussia, G. E., \& Kinicki, A. J. 1996. A motivational investigation of group effectiveness using social-cognitive theory. Journal of Applied Psychology, 81: 187-198.

Ronen, S. \& Shenkar, O. 1985. Clustering countries on attitudinal dimensions: a review and synthesis. Academy of Management Review, 10: 435-454.

Rosti, Jr., R. T., \& Shipper, F. 1998. A study of the impact of training in a management development program based on 360 feedback. Journal of Managerial Psychology, 13: 77-89.

Rozell, E. J., Pettihohn, C. E., \& Parker, R. S. 2000. Measuring emotional intelligence: The impact on management education. Paper presented at the Academy of Management Meetings, August 2000. Toronto, Canada.

Salovey, P., \& Mayer, J. 1990. Emotional intelligence. Imagination, Cognition, and Personality, 9: 185-211.

Scherer, K. R. \& Wallbott, K. G. 1994. Evidence for universality and cultural evaluation of differential emotion response patterning. Journal of Personality and Social Psychology, 66: $310-328$.

Schriesheim, C. A., \& Kerr, S. 1974. Psychometric properties of the Ohio State leadership scales. Psychological Bulletin, 81: 756-765.

Schutte, N. S., Malouff, J. M., Hall, L. E., Haggerty, D. J., Cooper, J. T., Golden, C. J., \& Dornheim, L. 1998. Development and validation of a measure of emotional intelligence. Personality and Individual Differences, 25: 167-177.

Shipper, F. 1991. Mastery and frequency of managerial behaviors relative to sub-unit effectiveness. Human Relations, 44: 371-388. 
Shipper, F. 1995. A study of the psychometric properties of the managerial skill scales of the survey of management practices. Educational and Psychological Measurement, 55: 468-479.

Shipper, F., \& Davy, J. 2002. A model and investigation of managerial skills, employees' attitudes and managerial performance. Leadership Quarterly, 13: 95-120.

Shipper, F., \& Dillard, J. E. 2000. A study of impending derailment and recovery among middle managers across career stages. Human Resource Management Journal, 39: 331-345.

Shipper, F., \& White, C. S. 1999. Mastery, frequency \& interaction of managerial behaviors relative to subunit effectiveness. Human Relations, 52: 49-66.

Shipper, F., \& Wilson, C. L. 1992. The impact of managerial behaviors on group performance, stress and commitment. In K. E. Clark, M. B. Clark \& D. P. Campbell (Eds.), Impact of leadership (pp. 119-129). Greensboro, NC: Center for Creative Leadership.

Shore, L.M., Tetrick, L.E., \& Shore, T. H. 1998. A comparison of self, peer, and assessor evaluations of managerial potential. Journal of Social Behavior and Personality, 13: 85101.

Sosik, J. J., \& Megerian, L. E. 1999. Understanding leader emotional intelligence and performance: The role of self-other agreement on transformational leadership perceptions. Group \& Organization Management, 24: 367-390.

SPSS. 1997. Table Curve 3D. Chicago, SPSS Inc.

Van Velsor, E., \& Leslie, J. B. 1991. Feedback to managers, Volume II: A review and comparison of sixteen multi-rater feedback instruments. Greensboro, NC: Center for Creative Leadership. 
Van Velsor, E., Taylor, S., \& Leslie, J. B. 1992. Self/rater agreement, self-awareness and leadership effectiveness. Paper presented at the annual convention of the American Psychological Association. American Psychological Association, Washington, DC, August.

Venables, W. N. \& Ripley, B. D. 2002. Modern applied statistics with $S$ (4 ${ }^{\text {th }}$ ed.). New York: Springer-Verlag.

Wilson, C. L. 1975. Multi-level management surveys: Feasibility studies and initial applications. JSAS: Catalog of Selected Documents in Psychology, vol. 5 (Ms. No. 1137). Washington: American Psychology Association.

Wilson, C. L. 1978. The Wilson multi-level management surveys: Refinement and replication of the scales. JSAS: Catalog of Selected Documents in Psychology, vol. 8 (Ms. No. 1707. Washington: American Psychology Association.

Wilson, C. L., O'Hare, D., \& Shipper, F. 1990. Task cycle theory: The process of influence. In K. E. Clark \& M. B. Clark (Eds.), Measures of leadership (pp. 185-204). West Orange, NJ: Leadership Library of America, Inc.

Wilson, C. L., \& Wilson, J. L. 1991. Teams and leaders: A manual for the Clark Wilson Publishing Company training and development programs. Silver Spring: Clark Wilson Publishing Company.

Wilson, C. L., Wilson, J. L., \& Wilson, K. B. 1996. Meaningful measures. Silver Spring, MD: Clark Wilson Group, Inc.

Yukl, G. A. 1989. Leadership in organizations (2nd ed.). Englewood Cliffs: Prentice Hall. Yukl, G. A. 1998. Leadership in organizations (4th ed.). Englewood Cliffs: Prentice Hall. 
Table 1

National Socio-cultural Characteristics

\begin{tabular}{|c|c|c|c|}
\hline $\begin{array}{l}\text { Socio-cultural } \\
\text { Characteristics }\end{array}$ & Malaysia & United Kingdom & United States \\
\hline Cultural cluster & Far eastern & Anglo & Anglo \\
\hline $\begin{array}{l}\text { Values: } \\
\text { Power distance - degree of } \\
\text { inequality among social } \\
\text { levels and acceptance of } \\
\text { authority }\end{array}$ & $\begin{array}{l}\text { High } \\
(104)\end{array}$ & $\begin{array}{l}\text { Low } \\
(35)\end{array}$ & $\begin{array}{l}\text { Low } \\
(40)\end{array}$ \\
\hline $\begin{array}{l}\text { Uncertainty Avoidance - } \\
\text { fear of the unknown or } \\
\text { ambiguous }\end{array}$ & $\begin{array}{l}\text { Low } \\
(36)\end{array}$ & $\begin{array}{l}\text { Low } \\
(35)\end{array}$ & $\begin{array}{l}\text { Low } \\
(46)\end{array}$ \\
\hline $\begin{array}{l}\text { Self-orientation - identity } \\
\text { based on the individual } \\
\text { versus a group }\end{array}$ & $\begin{array}{l}\text { Collective } \\
\text { (26) }\end{array}$ & $\begin{array}{l}\text { Individual } \\
\qquad(89)\end{array}$ & $\begin{array}{l}\text { Individual } \\
\qquad(91)\end{array}$ \\
\hline $\begin{array}{l}\text { Assertiveness - preference } \\
\text { for competition and results } \\
\text { (masculine) versus } \\
\text { cooperation and quality } \\
\text { (feminine) }\end{array}$ & $\begin{array}{l}\text { Masc-Fem. } \\
\qquad(50)\end{array}$ & $\begin{array}{l}\text { Masculine } \\
\text { (66) }\end{array}$ & $\begin{array}{l}\text { Masculine } \\
\quad(62)\end{array}$ \\
\hline Ethnic Groups & $\begin{array}{c}\text { Malay } 58 \%, \\
\text { Chinese } 27 \% \text {, etc. }\end{array}$ & Anglo $91 \%$ & $\begin{array}{c}\text { Caucasian } \\
81.5 \%\end{array}$ \\
\hline Religion & Muslim & $\begin{array}{l}\text { Church of } \\
\text { England }\end{array}$ & Protestant \\
\hline Language & Malay & English & English \\
\hline Region & Southeast Asia & Western Europe & North America \\
\hline
\end{tabular}

Sources: CIA World Facts, 2001; Hofstede, 2001; Ronen and Shenkar, 1985. 
Table 2

Psychometric Properties of Managerial Skill Scales

\begin{tabular}{|c|c|c|c|}
\hline Managerial Skills & $\underset{\mathrm{n}}{\text { Alpha }}$ & $\mathrm{r}_{\mathrm{WG}(\mathrm{J})}$ &,$^{2}$ \\
\hline $\begin{array}{l}\text { 1. Clarification of Goals and } \\
\text { Objectives }\end{array}$ & $\begin{array}{l}.88 \\
32989\end{array}$ & .91 & .35 \\
\hline $\begin{array}{l}\text { 2. Upward Communication/Participa- } \\
\text { tion }\end{array}$ & $\begin{array}{c}.88 \\
33414\end{array}$ & .91 & .36 \\
\hline 3. Orderly Work Planning & $\begin{array}{c}.93 \\
3854\end{array}$ & .93 & .40 \\
\hline 4. Organizational Expertise & $\begin{array}{c}.86 \\
3364\end{array}$ & .92 & .41 \\
\hline 5. Work Facilitation & $\begin{array}{c}.87 \\
32784\end{array}$ & .90 & .37 \\
\hline 6. Feedback & $\begin{array}{c}.87 \\
32623\end{array}$ & .89 & .33 \\
\hline 7. Time Emphasis & $\begin{array}{c}.84 \\
32777\end{array}$ & .91 & .35 \\
\hline 8. Control of Details & $\begin{array}{c}.77 \\
32568\end{array}$ & .87 & .42 \\
\hline 9. Goal Pressure & $\begin{array}{c}.82 \\
31983 \\
\end{array}$ & .86 & .46 \\
\hline 10. Delegation/Permissiveness & $\begin{array}{c}.89 \\
32710\end{array}$ & .92 & .37 \\
\hline $\begin{array}{l}\text { 11. Recognition for Good } \\
\text { Performance }\end{array}$ & $\begin{array}{c}.95 \\
33765 \\
\end{array}$ & .91 & .34 \\
\hline
\end{tabular}


Table 3

Associates' Component Score Coefficients and Factor Correlations

\begin{tabular}{|c|c|c|c|c|c|c|}
\hline & \multicolumn{2}{|c|}{ U S Factors } & \multicolumn{2}{|c|}{ UK Factors } & \multicolumn{2}{|c|}{$\begin{array}{l}\text { Malaysian } \\
\text { Factors }\end{array}$} \\
\hline & 1 & 2 & 1 & 2 & 1 & 2 \\
\hline Goal Clarity & .150 & .055 & .138 & .104 & .123 & .025 \\
\hline Participation & .141 & -.149 & .155 & -.162 & .126 & -.161 \\
\hline Orderly Work Planning & .136 & .098 & .129 & .126 & .120 & -.027 \\
\hline Organizational Expertise & .141 & -.028 & .143 & .088 & .121 & -.042 \\
\hline Facilitation & .153 & -.018 & .156 & -.022 & .128 & -.047 \\
\hline Feedback & .142 & .078 & .141 & .050 & .113 & .112 \\
\hline Time Emphasis & .105 & .276 & .090 & .274 & .086 & .308 \\
\hline Control of Details & .054 & .401 & .044 & .363 & .098 & .206 \\
\hline Goal Pressure & -.045 & .394 & -.053 & .406 & -.024 & .734 \\
\hline Delegation & .110 & -.282 & .133 & -.269 & .120 & -.228 \\
\hline Recognition & .131 & -.044 & .140 & -.134 & .120 & -.042 \\
\hline $\begin{array}{l}\text { Correlation Between } 1 \& 2 \text { Within } \\
\text { Culture }\end{array}$ & \multicolumn{2}{|c|}{$.165 * *$} & \multicolumn{2}{|c|}{.076} & \multicolumn{2}{|c|}{$.156^{* *}$} \\
\hline \multicolumn{3}{|c|}{ Correlation Between US \& Other Culture $1^{\text {st }}$ Factor } & \multicolumn{2}{|c|}{$.999 * * *$} & \multicolumn{2}{|c|}{$.999 * * *$} \\
\hline \multicolumn{3}{|c|}{ Correlation Between US \& Other Culture $2^{\text {nd }}$ Factor } & \multicolumn{2}{|c|}{$.997 * * *$} & \multicolumn{2}{|c|}{$.921 * * *$} \\
\hline
\end{tabular}

Note: $* *$ indicates $\Delta<.01 ; * * *$ indicates $\Delta<.001$ 
Table 4

Self Component Score Coefficients and Factor Correlations

\begin{tabular}{|c|c|c|c|c|c|c|}
\hline & \multicolumn{2}{|c|}{ US Factors } & \multicolumn{2}{|c|}{ UK Factors } & \multicolumn{2}{|c|}{$\begin{array}{l}\text { Malaysian } \\
\text { Factors }\end{array}$} \\
\hline & 1 & 2 & 1 & 2 & 1 & 2 \\
\hline Goal Clarity & .167 & .060 & .164 & .023 & .130 & .072 \\
\hline Participation & .161 & -.189 & .163 & -.166 & .157 & -.194 \\
\hline Orderly Work Planning & .131 & .139 & .144 & .052 & .119 & .059 \\
\hline Organizational Expertise & .159 & .023 & .157 & -.021 & .121 & .083 \\
\hline Facilitation & .177 & -.041 & .166 & .002 & .142 & -.004 \\
\hline Feedback & .163 & .049 & .154 & .042 & .133 & .014 \\
\hline Time Emphasis & .127 & .217 & .112 & .233 & .106 & .157 \\
\hline Control of Details & .025 & .421 & -.005 & .515 & .033 & .420 \\
\hline Goal Pressure & -.012 & .405 & -.030 & .458 & -.053 & .643 \\
\hline Delegation & .137 & -.308 & .149 & -.271 & .152 & -.203 \\
\hline Recognition & .151 & -.078 & .134 & -.012 & .140 & -.090 \\
\hline Correlation Between $1 \& 2$ Within Culture & \multicolumn{2}{|c|}{$.071 * *$} & \multicolumn{2}{|c|}{$.153 *$} & \multicolumn{2}{|c|}{$.313 * *$} \\
\hline \multicolumn{3}{|c|}{ Correlation Between US \& Other Culture $1^{\text {st }}$ Factor } & \multicolumn{2}{|c|}{$.999 * * *$} & \multicolumn{2}{|c|}{$.999 * * *$} \\
\hline \multicolumn{3}{|c|}{ Correlation Between US \& Other Culture $2^{\text {nd }}$ Factor } & \multicolumn{2}{|c|}{$.988 * * *$} & \multicolumn{2}{|c|}{$.978 * * *$} \\
\hline
\end{tabular}

Note: $*$ indicates $\Delta<.01 ; * *$ indicates $\Delta<.01 ; * * *$ indicates $\Delta<.001$ 
Table 5

Quadratic Equations for Self-Awareness

\begin{tabular}{|l|r|c|c|c|c|c|c|c|c|c|c|}
\hline & & $\mathrm{a}$ & $\mathrm{bx}$ & $\mathrm{cy}$ & $\mathrm{dx}^{2}$ & $\mathrm{ey}^{2}$ & $\mathrm{fxy}$ & $\mathrm{DF}$ & $\mathrm{F}$ & $\rho<$ & $\mathrm{R}^{2}$ \\
\hline United & Interactive & 5.66 & .07 & .16 & -.08 & -.01 & .21 & 2,255 & 125.69 & .00001 & .72 \\
& $\rho<$ & .00001 & .05 & .00001 & .00001 & $\mathrm{~N} / \mathrm{S}$ & .00001 & & & & \\
\cline { 2 - 13 } & Controlling & 4.11 & -.07 & .09 & .13 & .28 & -.30 & 2,255 & 89.39 & .00001 & .64 \\
& $\rho<$ & .00001 & $\mathrm{~N} / \mathrm{S}$ & $\mathrm{N} / \mathrm{S}$ & .00001 & .00001 & .00001 & & & & \\
\hline United & Interactive & 5.37 & -.31 & .78 & -.33 & -.27 & .39 & 2,255 & 24.98 & .00001 & .56 \\
Kingdom & $\rho<$ & .00001 & .00001 & .00001 & .00001 & .00001 & .00001 & & & & \\
\cline { 2 - 13 } & Controlling & 5.17 & .14 & .17 & -.29 & -.03 & .18 & 2,255 & 19.71 & .00001 & .28 \\
& $\rho<$ & .00001 & .05 & .001 & .00001 & $\mathrm{~N} / \mathrm{S}$ & .00001 & & & & \\
\hline \multirow{5}{*}{ Malaysia } & Interactive & 5.20 & .32 & -.20 & .06 & -.16 & -.22 & 2,255 & 24.98 & .00001 & .33 \\
& $\rho<$ & .00001 & .00001 & .0001 & $\mathrm{~N} / \mathrm{S}$ & .00001 & .00001 & & & & \\
\cline { 2 - 12 } & Controlling & 4.93 & -.74 & .56 & -.10 & .25 & .11 & 2,255 & 35.77 & .00001 & .42 \\
& $\rho<$ & .00001 & .00001 & .00001 & $\mathrm{~N} / \mathrm{S}$ & .00001 & .05 & & & & \\
\hline
\end{tabular}

Note: $\mathrm{X}$ is for the self-score; $\mathrm{Y}$ is for the associates' score; the statistical significance of the coefficient each term appears directly below it; and N/S means non-significant. 
Figure 1

Levelplot of Managerial Effectiveness

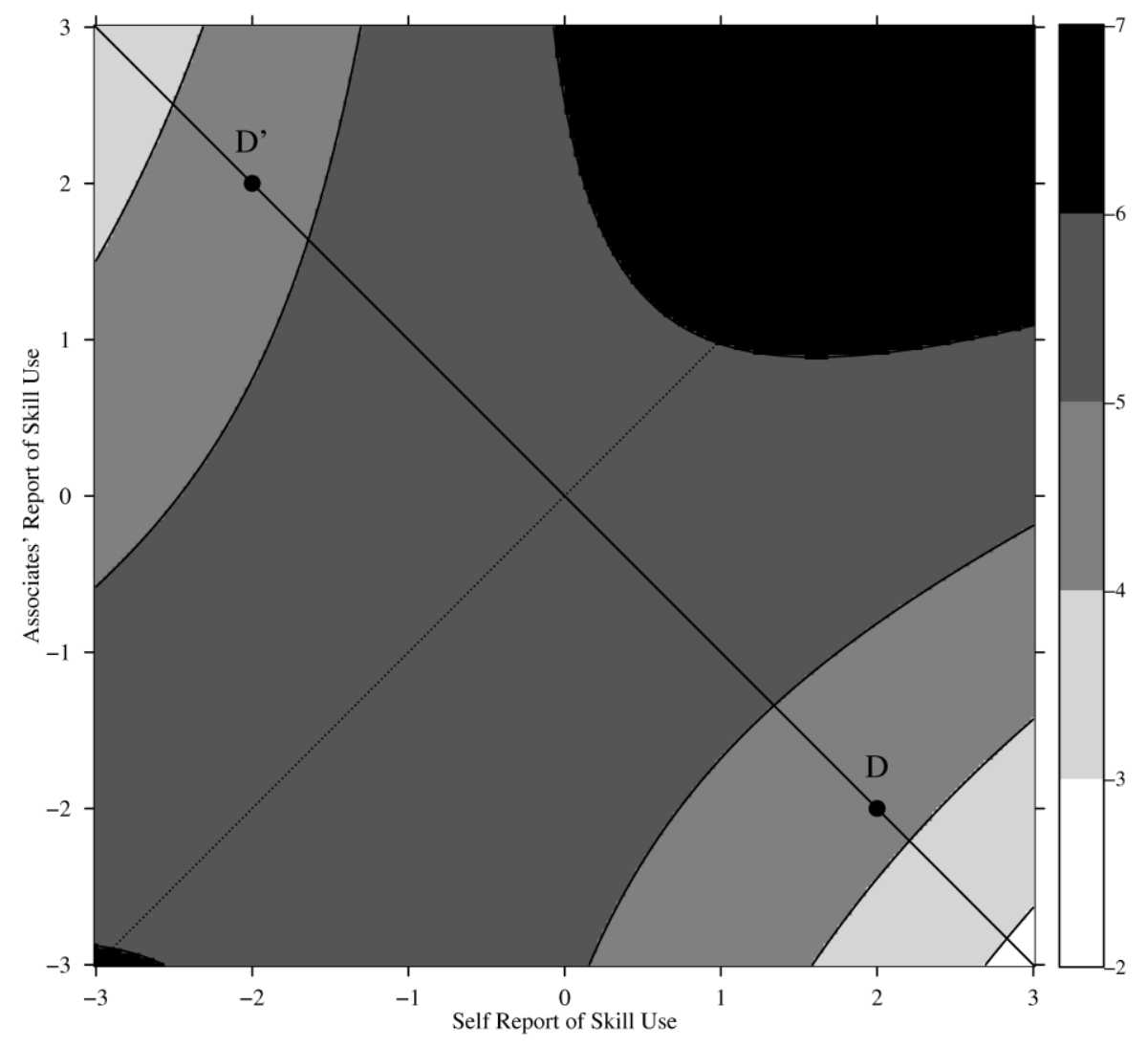


Figure 2

Managerial Effectiveness as a Function of Reported Skill Use

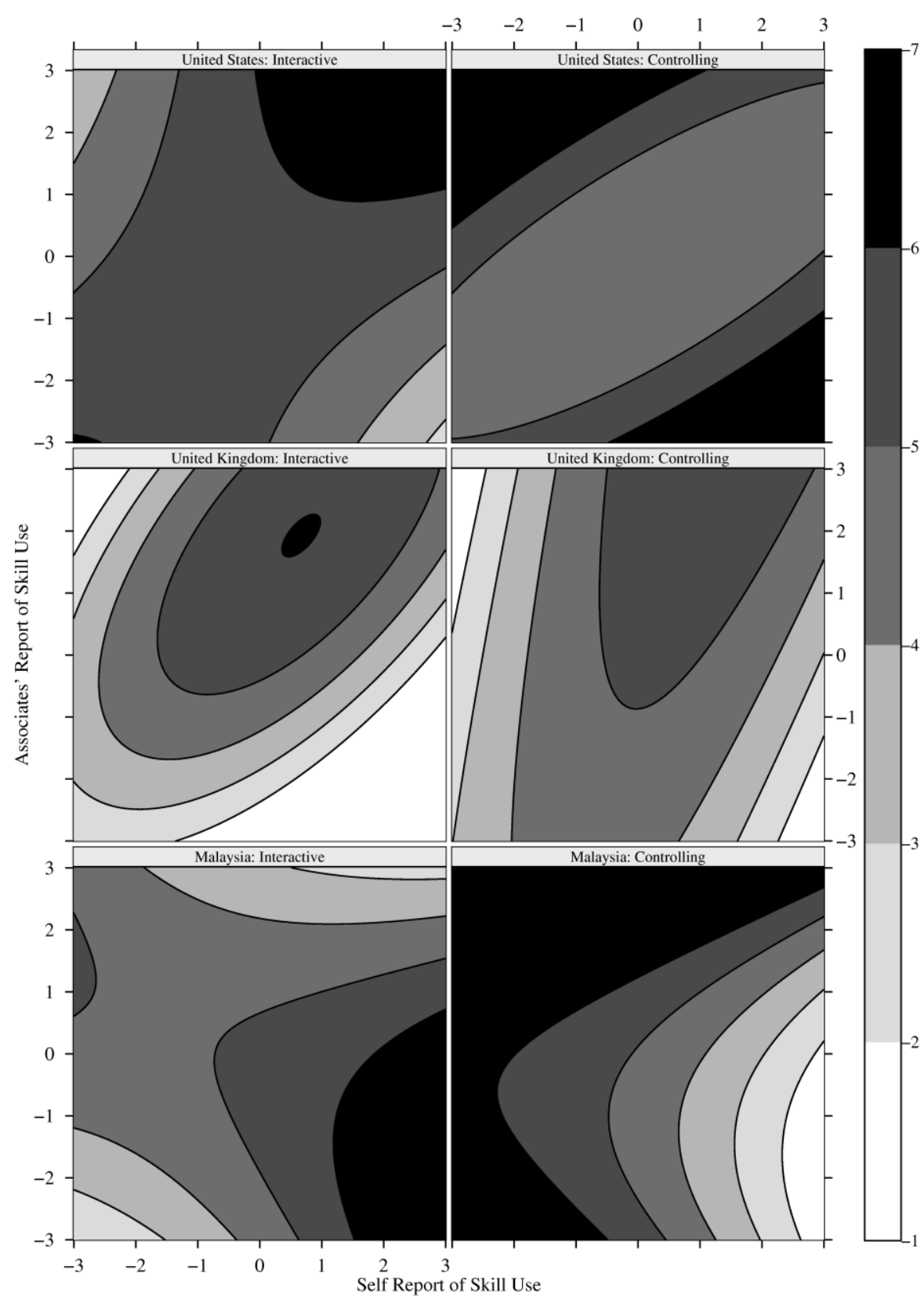

